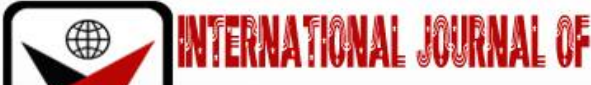

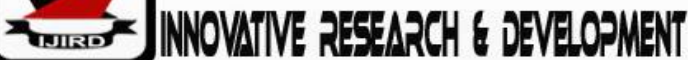

ISSN 2278 - 0211 (Online)

\section{Re-usable Cloth Facemasks in the Covid-19 Era}

\begin{tabular}{c} 
Francis Ongachi Olal \\
Senior Lecturer, Department of Physical Sciences, Rongo University, Kenya \\
Phoebe Owiti \\
Lecturer, Department of Physical Sciences, Rongo University, Kenya \\
Nelima Barasa \\
Assistant Lecturer, Department of Physical Sciences, Rongo University, Kenya \\
Monica Oguta \\
Assistant Lecturer, Department of Physical Sciences, Rongo University, Kenya \\
\hline
\end{tabular}

\begin{abstract}
:
Following the World Health Organization designating the 'corona virus disease 2019' (COVID-19) a global pandemic, there has been a global demand for production of PPEs (Personal Protection Equipment) to help fight the scourge. As there has been growing numbers of people getting infected, respective global governments and WHO have suggested necessary needs and measures to reduce escalation. In Kenya, the government has taken steps such as insisting on social distancing, encouraged use of face masks and controlled movement among other measures to slow the rate of transmission. These actions prevent a strain on the healthcare system which already has shortages of key equipment. Using textile technology and design, this study seeks to implement knowledge of the field to focus on protective measures that will immediately address prevention of the spread. The study focused on the development and testing of face masks for the public to help in prevention of COVID -19 spread. These masks were made from natural cotton fibre that is affordable, available and reusable. The mask was made using three layers of 7" by 7" pieces of fabric. The two outer layers were made of poly-cotton, while the middle layer was polypropylene fabric, used as a filter. Users of this product breathe comfortably through a double-layer of brand new poly cotton. Putting masks on the sick reduces their ability to spread the virus. It is generally believed that the primary purpose of cloth masks is to prevent spread of infections from the wearer.
\end{abstract}

Keywords: COVID -19, pandemic, facemask, healthcare, PPE

\section{Introduction}

Globally, humanity is grappling with the outbreak of COVID-19. There has been a rapid spread across the globe with increasing death tolls across the continents. The increase in the COVID-19 pandemic has made governments to intensify measures to protect their citizens from the virus. With a current COVID-19 pandemic, many individuals may be infected but asymptomatic, spreading the virus without realizing it. Besides, quite a number of healthy people may not be able to adequately isolate themselves from infected partners, family members, and housemates. In the absence of vaccination, respirators and masks can be worn to prevent transmission of airborne pathogenic aerosols and control diseases such as COVID- 19. Therefore apart from staying at home and social distancing, the use of masks by all citizens when in public places has been emphasized. The use of masksisa standard practice in countries like Hong Kong, Singapore, and other parts of Asia (Kamplaset al., 2020). Re-usable cloth facemasks are commonly used in low and middle income countries (Bradsher \& Alderman, 2020). It is generally believed that the primary purpose of cloth masks is to prevent spread of infections from the wearer. However, historical evidence shows that they have previously been used to protect health care workers from respiratory infections (Van der Sande et al., 2020). A challenge that many third world countries encounter is the power to meet the demand for masks.In addition, the severe acute respiratory syndrome - coronavirus 2 (SARS-CoV-2) has led to shortage in surgical masks and N95 masks. This therefore has opened a window for the use of cotton cloth masks to aid in meeting the demand for masks in the COVID-19 Era. According to public health expert Shan Soe-Lin and epidemiologist Robert Hecht, we need to change our perception that masks are only for sick. They suggested that if more people wore masks it would become a social norm and a public health good (Soe-Lin \& Hecht, 2020).

As the number of cases in Kenya continues to grow, hospitals are already reporting shortages of key equipment needed to care for critically ill patients and personal protective equipment (PPE) such as cloth facemasks for health workers and the community at large (WHO, 2020). Adequate production and distribution of cloth facemasks are crucial during the pandemic. As Kenya supports for a growing wave of patients with Covid-19 in hospitals and ICUs, it must be ensured that there are key equipment needed to care for patients and to keep health care workforce safe (Van der Sande $e t$ al., 2020). Achieving this goal requires a concerted approach from all sectors, from local and national government to the 
private sector and health care providers themselves. The lack of recommendations for respiratory protection may be due to a lack of evidence on their efficacy (Jacobs et al.,2020). For most low income countries like Kenya, it is highly unlikely that they will be able to provide disposable masks, let alone respirators for that extended period of time and may have to ration the use of these products during this extended outbreak of COVD-19 pandemic. Therefore, the use of re-usable cloth masks may be the only option available for Kenyans.

Several studies have tested the performance of masks improvised from household materials. A study by (Davies et al., 2013) compared the filtration efficiency of surgical masks to linen, silk, a scarf, a kitchen towel, a pillowcase, a vacuum cleaner bag, and masks that volunteers made from 100 percent cotton T-shirts. According to Seongmanet al., (2020) Cloth masks for COVID-19 Era can be best produced using fabric with a high filtration capacity. The author further indicated that the Federal health officials have recommended that people cover their faces with fabric in the COVID-19 Era. The question that remains unanswered is that what material offers the best protection. The Center for Disease Control and prevention has not given any sewing guidelines on the use of a bandana, coffee filter, rubber bands and folded fabrics found at home. This therefore gives way to make rectangular cloth masks with three pleats on both sides with elastic loops like the surgical masks.

Research indicate that a cloth mask made from a dense fabric that is able to capture viral particles but breathable enough will work better in preventing COVID-19 (Seongman, et al.; 2020). Maclntyre et al., (2015), indicated that a two layered cloth mask captures less particles compared to a three-layered cloth mask. For example, a 600-thread count pillow case captured $22 \%$ of particles when doubled while four layers captured nearly 60\%.According to Brand (2020), best performing cloth masks were constructed of two layers of high quality, heavy weight cotton quilters; two-layer mask made with thick batik fabric and a double layer mask with an inner layer of flannel and outer layer of cotton.

Chughtai et al., (2013) outlined that the function of the health and hygiene product is to do infection control by providing maximum comfort. The principal design features of fabric, weather reusable or disposable, utilized as medical textiles must meet minimum performance standards for barrier protection, sterilization stability, breath ability \& comfort, low linting, economical and environment friendly (Seongman, et al., 2020).Earlier on Davieset al.,(2013) suggested that the effectiveness of clothe masks is associated with the type of fabric, increasing fineness of the fabric and the number of layers used to make a mask.

A research done by, Chughtai, et al, (2013), compared a four-layer cotton mask, with a mask made from two layers of woven cambric with a piece of paper in between and a paper mask surrounded by cellulose wadding. All three masks were found effective in preventing spread of staphylococcal infection. Later on, Maclntyre et al., (2015), evaluated a twolayer gauze mask and found that it was effective in blocking particles greater than $4 \mu \mathrm{m}(99.6 \%)$ and less than $4 \mu \mathrm{m}$ (96.7\%). The results by above authors shows that well designed cotton masks may be effective in preventing infection.

\section{Methods and Materials}

\subsection{Materials}

- Poly cotton fabric

- Polypropylene fabric

- $\quad$ Needle and thread (or bobby pin)

- Scissors

- Sewing machine

- $\quad 0.5 \%$ Chlorine Solution

- Sanitizer

\subsection{Method}

The working room was fumigated using $0.5 \%$ concentration of chlorine solution. The dust coats used by the tailors were also disinfected using $0.5 \%$ concentration of chlorine solution. The tailors put on the surgical masks to avoid spreading of the pathogens on to the cloth masks which were being made. The tailors sanitized their hands frequently. According to the Kenya Bureau of Standards KS 2636: 2016, the cloth mask produced in this study was a type 4 mask. The Mask was made using three layers of 7" by 7" pieces of fabric. The two outerlayers were made of poly-cotton of various colours, while the middle layer was polypropylene fabric which was used as a filter (Figure 1).

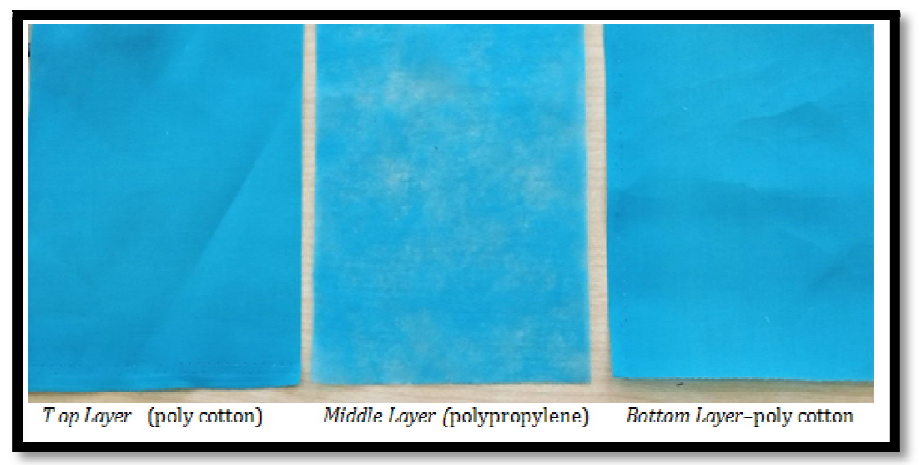

Figure 1: Three Layers of Fabric Required for Making the Mask 
All the three layers were put together in the order mentioned above with the wrong side facing up, then pleated horizontally with three pleats of $15 \mathrm{~mm}$ finished depth. The pleats faced downwards at the front part of the mask (Figure 2).

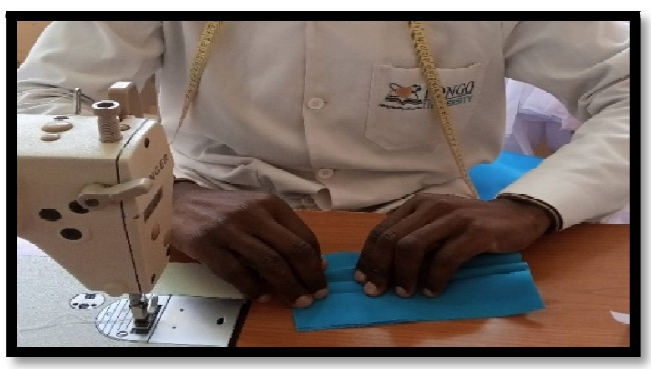

Figure 2: Pleating the Three Layers

The pleated pieces were stitched vertically on both sides to hold them together (Figure 3). The pleats were secured with binding on both sides while taking extra care to keep all pleats facing downward.

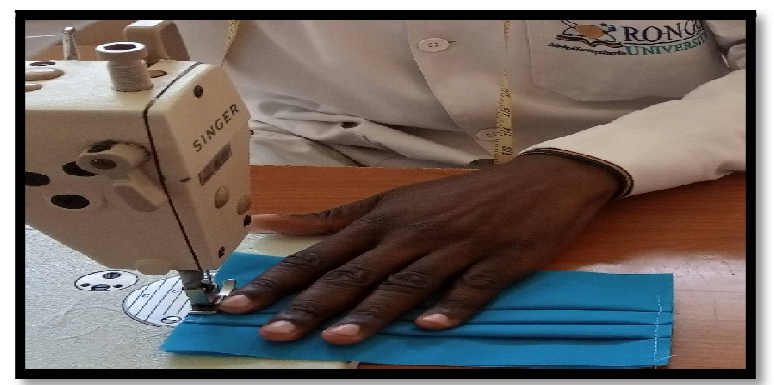

Figure 3: Holding the Pleats in Position

The top part of the mask was bound with a strip to a depth of $15 \mathrm{~mm}$ (Figure 4).

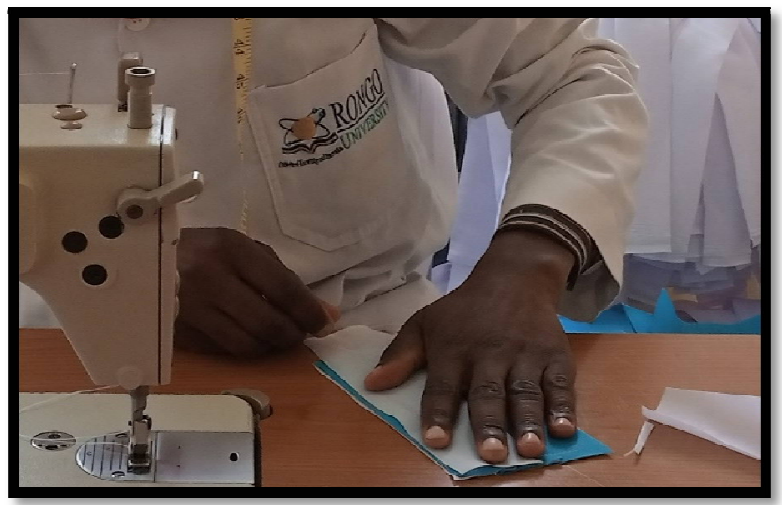

Figure 4: Binding the Top Part with a Strip

The bottom part of the mask was bound with a strip to a depth of $10 \mathrm{~mm}$.

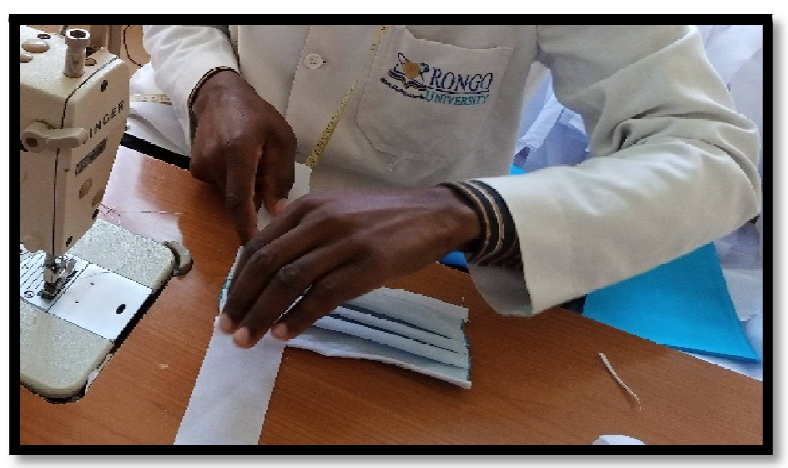

Figure 5: Fixing the Strip in Position 


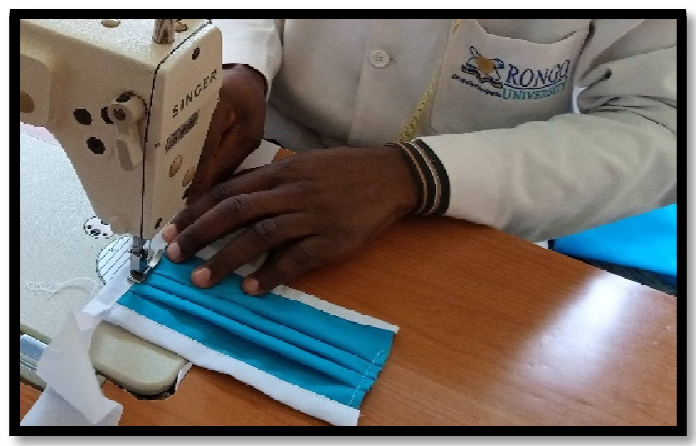

Figure 6: Stitching Into the Strip of the Mask.

Each side of the mask was bound with a strip to a depth of $10 \mathrm{~mm}$ which was folded and continued in each direction beyond the mask to give a tie of $380 \mathrm{~mm}$.

\section{Results and Discussion}

Figure 7 below shows three pleats of $15 \mathrm{~mm}$ depth made on the top part of the mask facing downwards.

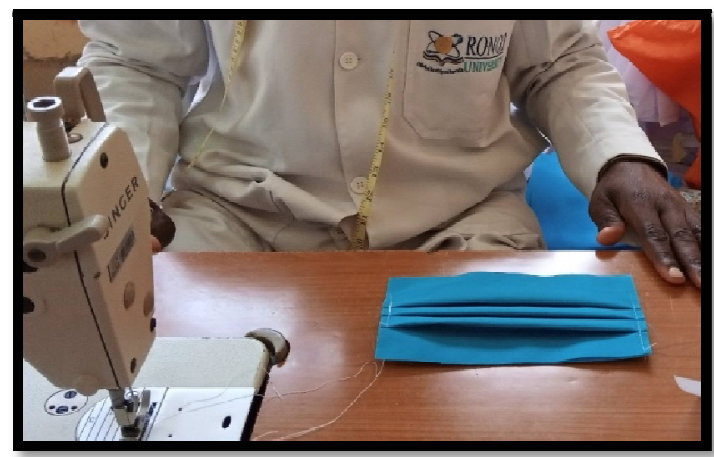

Figure 7: Three Pleats Created on the Mask

The complete piece of the mask bound with a white strip on the lengthwise is shown in Figure 8.

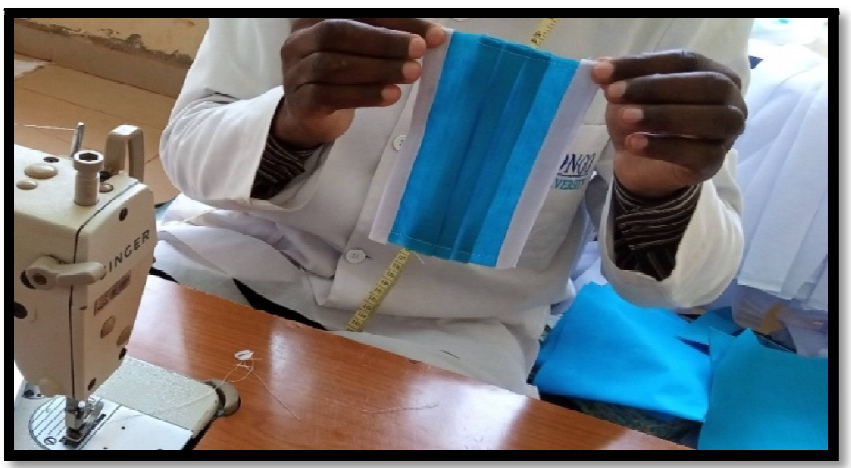

Figure 8: The Mask Bound on the Lengthwise Sides

The complete mask with the widthwise binding extending to form strips for tying is shown in Figure 9.

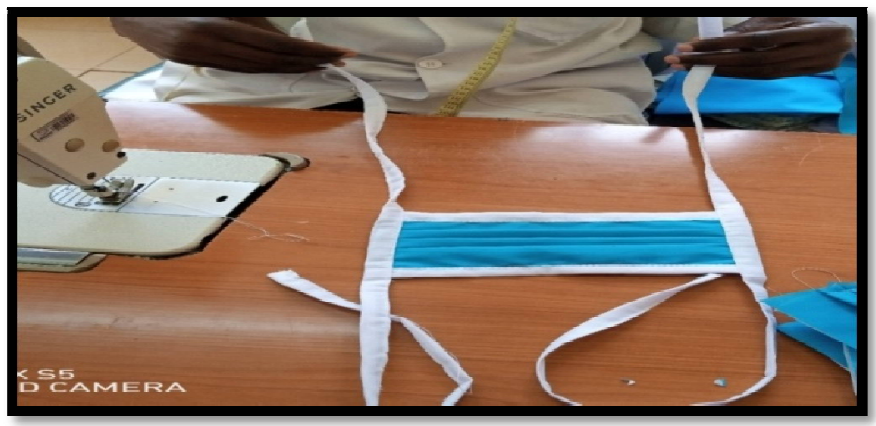

Figure 9: The Mask Bound with White Strips on Both Sides

The following are the completed masks, well ironed (Figure $10 \mathrm{a}, \mathrm{b}, \mathrm{c}$ ) 

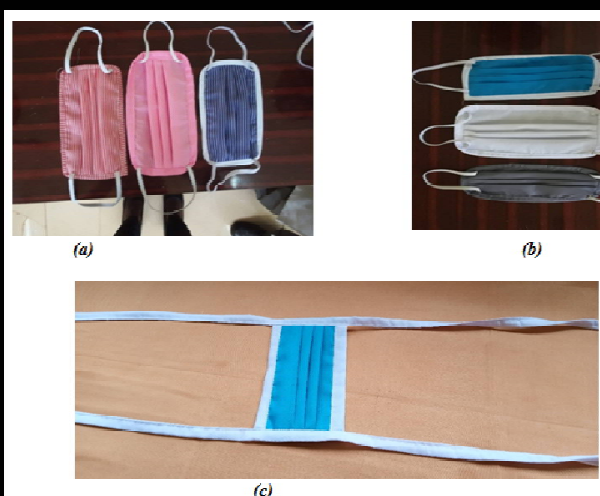

Figure 10: Completed Masks
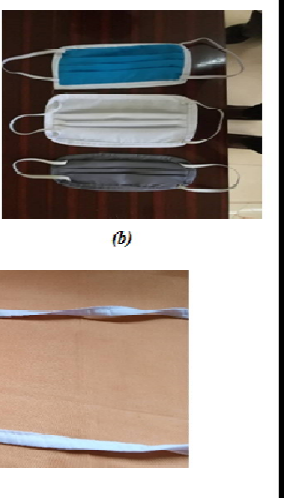

Given in Figure 11 a, b, c, d, e below are the completed masks worn and well fitting?

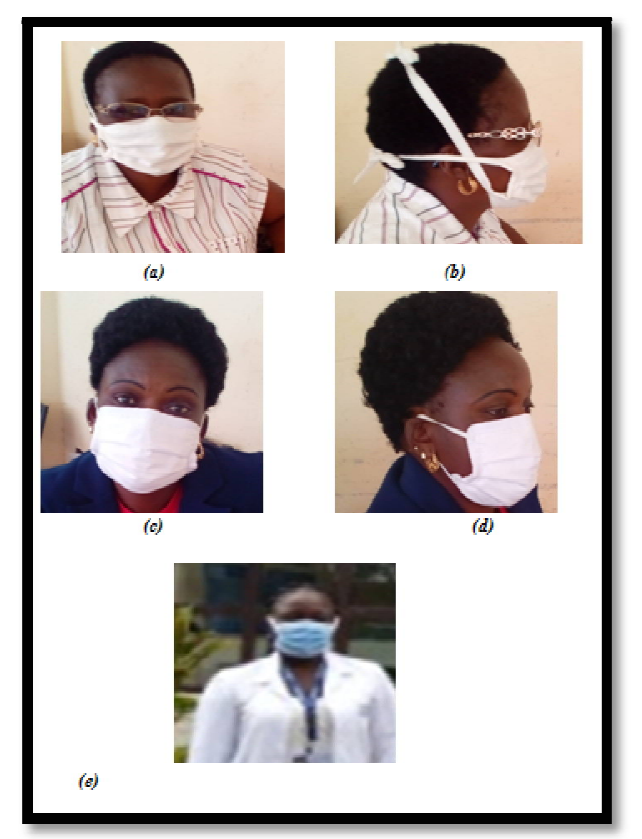

Figure 11: Completed Masks Worn and Fitting

The production and use of reusable cloth masks during the Covid-19 era aids in preventing the general public from transmitting the disease to others. Public masking theoretically works to drive down transmission at the population level. When a large portion of the population is wearing masks, both asymptomatic spreaders of the pathogen as well as the healthy will be masked. The key to public masking as transmission control is in source reduction. Putting masks on the sick reduces their ability to spread the virus. It is generally believed that the primary purpose of cloth masks is to prevent spread of infections from the wearer. However, historical evidence shows that they have previously been used to protect health care workers from respiratory infections. Unfortunately, randomized trials to examine the effectiveness of public masking have not designed their studies with these dynamics in mind. Instead the trials have looked at public masking to prevent getting sick, rather than as a source reduction.

\section{Conclusions and Recommendations}

Current literature suggests cloth masks are somewhat effective in protecting the general public from Covid-19. The evidence from historical studies, filtration studies, and observational studies combined with the simple logic of masking asymptomatic transmitters of SARS-CoV-2 together suggests that mass public masking may be an important public health intervention. This study therefore recommends that the health sector should educate the public on the importance of masking using reusable cloth masks to prevent getting sick. In addition, the study recommends that the Kenya Bureau of Standards should move with speed in providing accurate standards on reusable cloth facemasks.

\section{References}

i. Bradsher, K., Alderman, L. The world needs masks. China makes them - but has been hoarding them. New York Times. March16, 2020 (https://www.nytimes.com/2020/03/13/business/masks-china-coronavirus.html. opens in new tab. (Accessed 18 April 2020)

ii. Brand, M. (2020, April 8). Homemade Masks for COVID-19: What works, What doesn't. Retrieved from www.kcrw.com 
iii. Chughtai, A. A., Seale, H., \& MacIntyre, C. R. (2013). Use of cloth masks in the practice of infection control evidence and policy gaps. International Journal of Infection Control, 1-12.

iv. Daries, A., Thompson, K. A., Giri, K., Kafatos, G., Walker, J., \& Bennett, A. (2013, August 12). Testing the Efficacy of Home Made Masks, would they Protect in an Influenza Pandemic. Disaster Medicine and Public Health Preparedness., pp. 1-6.

v. Jacobs, A., Richtel, M. \&Baker M. 'At war with no ammo': doctors say shortage of protective gear is dire. New York Times. March19, $2020 \quad$ (https://www.nytimes.com/2020/03/19/health/coronavirus-masksshortage.html. opens in new tab). (Accessed 18 April 2020).

vi. Klampas, M., Morris, C. A., Sinclair, J., pearson, M., \& Shenoy, E. S. (2020, April 1). NEJM. Retrieved from NEJM.org.

vii. Maclntyre, R., Seale, H., Dung, T. C., Hien, N. T., Nga, P. T., Chughtai, A. A., ... Wang, Q. (2015, April 22). A cluster randomised trial of cloth masks compared with medical masks in healthcare workers. BJM Open.

viii. Seongman, S., Kim, M.-C., Kim, Y., Hee Cha, H., Seohin, J., Jung, J., . . . Kim, S. H. (2020, Aprill 6). Effectiveness of Surgical and Cotton Masks in Blocking SARS-CoV-2: A Controlled Comparison in 4 Patients. Annals of International Medicine.

ix. Soe-Lin, S., \& Hecht, R. (2020, 3 19). Guidance against wearing masks for the coronavirus is wrong- you should cover your face. Retrieved 4 14, 2020, from The Boston Globe: www.bostonglobe.com/2020/03/19/opinion/guidance-against-wearing-masks-for-the-coronavirus-is-wrongyou-should-cover--your-face/

x. Van der Sande, M. Teunis, P. \& Sabel R. Professional and home-made face masks reduce exposure to respiratory infections among the general population. PLoS ONE. 2020; 3:e2618. (Accessed 18 April 2020)

xi. World Health Organization. Home care for patients with COVID-19 presenting with mild symptoms and management of contacts: interim guidance. https://www.who.int/publications-detail/home-care-for-patientswith-suspected-novel-coronavirus-(ncov). (Accessed 18 April 2020). 